Jovana Fajgelj, master

Fakultet za pravne i poslovne studije dr Lazar Vrkatić
UDK: 811.131 .1

Pregledni naučni rad

Primljen: 28. 9. 2016.

Odobren: 18. 10. 2016.

\title{
ITALIJANSKA ARIJA - MOGUĆNOSTI PRIMENE U NASTAVI ITALIJANSKOG JEZIKA I KULTURE KAO STRANOG JEZIKA NA NIVOU A2
}

\begin{abstract}
ApstrakT: Rad se bavi predlozima nastavnih aktivnosti za učenje italijanskog jezika kao stranog na nivou A2 kroz melodramu. Operska arija je polazna tačka za vežbe gledanja/slušanja, čitanja, za diskusije i gramatička vežbanja. Na primerima parafraziranih tekstova arija na savremeni italijanski jezik studenti su u mogućnosti da uče jezik, ali i da budu u dodiru sa bogatim kulturnim nasleđem Italije. Upotrebom opere-filma, kao autentičnog didaktičkog materijala, studenti postaju deo italijanske kulture, što pozitivno utiče na njihovu motivaciju da razvijaju svoju komunikativnu kompetenciju kao i interkulturnu kompetenciju.
\end{abstract}

KLJUČNE REČI: opera-film, autentičan materijal, didaktika, kulturna kompetencija, komunikativna kompetencija.

Iskusio sam najveće zadovoljstvo u kantaktu sa operom. Ispunjavala me je srećom koju ne uspevam nigde drugde da pronadem.

Albert Ajnštajn

\section{Uvod}

U ovom radu probaćemo da prikažemo kako melodrama može da bude korisno didaktičko sredstvo za upoznavanje studenata, čije jezičko znanje odgovara nivou A2, sa italijanskom kulturom. Slušajući 
muziku, gledajući filmove snimljene na osnovu libreta, studentima su obezbeđena sredstva za upoznavanje sa jezikom i gramatičkim pravilima, kao i sa kulturnom i istorijskom baštinom Italije.

Sa didaktičke strane gledišta, upotreba filmskog materijala pokazuje se kao vrlo korisno sredstvo za razumevanje teksta uz pomoć slike, a studenti ujedno sagledavaju i jednu širu estetiku i kulturu, upoznaju se sa različitim nivoima izražavanja i postaju deo interakcije između teksta, muzike i filma.

\section{Opera kao amblem italijanskog jezika i kulture}

Kada je reč o melodrami, postoje ne samo brojni video-zapisi snimljeni u najpoznatijim svetskim pozorištima već i bogata i zanimljiva filmografija od 1900. godine pa sve do danas. Na taj način se otvorila jedna nova mogućnost širenja italijanske kulture u inostranstvo. Osim toga, činjenica je da je filmska industrija, i to ne samo italijanska, oslobodila veliki prostor za melodramu, prepričavajući, interpretirajući, parafrazirajući i šireći je po celom svetu.

Italijanski pevači, naročito tenori, postali su simboli i arhetipi italijanske muzike. Lirski repertoar, od melodrame sve do nedavnih kancona i pesama, raširio se sa druge strane okeana zahvaljujući migrantskim talasima čitavih italijanskih zajednica osamstotih godina. U velikom egzodusu iz Italije, koji je vodio ne samo u Sjedinjene Američke Države već i u Latinsku Ameriku i Australiju, muškarci, žene i deca preneli su, uz svoje kofere, i svoj jezik i kulturu. Italijanski jezik, kultura i identitet proširili su se tako po svetu, ostvarujući, sa jedne strane, zajednički život sa zemljom domaćinom, a sa druge strane, čvrsto su i nostalgično prenosili budućim generacijama autentičan italijanski duh. Odatle nam stižu ukusi i mirisi italijanske kuhinje, pesme najpoznatijih arija italijanskih opera, glas Enrika Karuza i Frenka Sinatre i drugih italijanskoameričkih izvođača.

Poslednjih nekoliko decenija radi se na popularizaciji italijanskog jezika i kulture u svetu kroz otvaranja instituta, kroz kongrese, naučne skupove, međunarodne forume, kurseve za učenje jezika na dal- 
jinu... Ujedno je, na jedan proporcionalan način, rasla i svesrdna podrška lirskom italijanskom repertoaru: od melodrame i njenih najpoznatijih izvođenja (Mocart, Rosini, Verdi, Pučini itd.) do velikih koncerata (concertoni) koji se prenose u celom svetu (u izvođenju tenora svetske slave, poput Pavarotija, Dominga, Karerasa itd.). Tako je italijanska opera danas najveći pozorišni izvoz (esportazione teatrale) (Balboni, Daloiso, 2007), a poruka koja se šalje kroz melodiju i belkanto oslikava čitav nacionalni identitet Italijana. Stoga možemo reći da nema učenja stranog jezika bez učenja strane kulture.

\section{Interkulturni pristup u nastavi jezika}

„Sva kultura je stvorena zahvaljujući jeziku, kroz jezik, a u velikoj meri i u jeziku" (Bugarski, 1997: 245). Nastava stranog jezika danas podrazumeva i učenje o kulturi drugog. Jezik i kultura su neodvojivi tokom učenja stranog jezika jer učenik treba da razvija svoja znanja i o kulturi drugog. Interkulturni pristup je samim tim sve više prisutan u nastavi jezika.

Komunikativna metoda je počela da se razvija 60 -ih godina jer se jezik više nije posmatrao kao sistem jezičkih formi, nego kao aspekt ljudske komunikacije, a od 80-ih godina učenje stranog jezika obogaćuje se sve više interkulturnim pristupom. Stoga, cilj nastave stranog jezika ne bi trebalo da bude samo sticanje lingvističkih kompetencija, već razumevanje kulturnog okvira i prihvatanje normi kulture u kojoj se ciljni jezik koristi kao maternji (Krasner, 1999). Na taj način je interkulturna kompetencija ${ }^{1}$ uzročno-posledično vezana za komunikativnu kompetenciju.

Balboni (1994) upućuje na to da kada se predaje kultura ili italijanska civilizacija (civiltà) treba se pozvati na dva antropološka pojma: kulturu koja se odnosi na celo nasleđe kulturnih modela koji se tiču ishrane, porodičnog jezgra, društvenog organizovanja itd. i civilizaciju koja se odnosi na one kulturne modele koji su prikazani u svetu kao primeri i rešenja na koja su Italijani ponosni: umetnost, melodrama, neorealizam, ravnopravnost polova, sloboda štampe,

\footnotetext{
1 „Interkulturna kompetencija je veština stvarne interakcije sa ljudima koji potiču iz različitih kultura" (Byram, navedeno u Vučo, 2013: 373).
}

CIVITAS | God. 6, Br. 1, 2016. 
ukidanje smrtne kazne itd. Prema istraživanju Vinjucija, želja da se prate pozorišni i melodramski komadi na italijanskom jeste prva motivacija za učenje stranog jezika $(19,4 \%)$, a na petom mestu je želja da se prate italijanski radio i televizija (8,2\%) (navedeno u Balboni: 109).

„Nastavnici, autori udžbenika više nisu ambasadori kulture drugoga, posmatrane kao statične, same sebi dovoljne i strane, već je njihova uloga u tome da uvaže i primene interaktivnu prirodu i društvene, političke i etičke implikacije učenja i nastave o kulturi“ (Vučo, 2013: 373). U okviru nastave italijanskog jezika kao drugog stranog jezika pred nastavnikom je težak zadatak da izdvoji ono što bi njegovim učenicima upotpunilo i proširilo znanje iz stranog jezika i kulture. Savremeni udžbenici italijanskog jezika prate nove tendencije u okviru interkulturnog pristupa. Kao dodatni materijal savremenim udžbenicima italijanskog jezika za strance navešćemo L' italiano all’opera - attività linguistiche attraverso 15 arie famose (Carresi, Chiarenza, Frollano, 1998). Dela koja se ovde obrađuju predstavljena su, sa jedne strane, kroz istorijsko-kritički osvrt, sa kritičkim i biografskim podacima o libretistima i kompozitorima, a sa druge strane ponuđene su vežbe za morfološku i sintaksičku analizu poznatih delova italijanskih opera.

\section{Italijanska arija - autentičan didaktički materijal}

„Strana kultura učenicima najčešće nije dostupna kao objektivna realnost, već kao slika ili njena predstava, u čijoj izgradnji nastavnik ima važnu ulogu“(Vujović, 2007: 663). Pored nastavnika, didaktički materijal jeste taj koji bi trebalo da pruži korisne informacije o stranoj kulturi i civilizaciji. Uz to, možemo studentima uvesti autentičan materijal ${ }^{2} \mathrm{u}$ vidu snimljenih filmova po libretima poznatih melodrama, slušanja muzike, što vodi ka memorisanju jezika, gramatičkih pravila, upoznajući ih istovremeno sa muzičkom kulturom Italije. Sa druge strane, čuju

\footnotetext{
2 Pravi se podela na autentičan materijal za odrasle i za decu. Prvoj kategoriji kojom se bavi ovaj rad pripadaju:

„snimci originalnih delova italijanskih filmova, snimci originalnih televizijskih prenosa, snimci originalnih italijanskih radio-emisija, književni odlomci, novinski članci, tekstovi pesama, pozorišni tekstovi, pisani murali, reklame, fotografije, vinjete, snimci razgovora, telefonskih poziva i razgovora uživo, konferencije, televizijske i radio debate, odlomci lirskih opera, poezija itd.“ (Comodi, 1995: 7).
} 
se glasovi kritike koji podsećaju da autentični jezički materijali mogu da budu frustrirajući jer zahtevaju lingvistička znanja i predznanja iz kulture, što učenici često nemaju (Harrich, 2011). U takvim situacijama nastavnik ima obavezu da učenika uputi u zadatak koji treba da uradi i da objasni da ne treba da ga ometa kompleksnost teksta.

„Razvoj sposobnosti slušanja jeste naročito važan jer između slušanja i govora postoji odnos međusobne zavisnosti, to jest bez slušanja ne postoji komunikacija“ (Harrich, 2011: 322). Ako učenik nije bio u dodiru sa autentičnim jezikom, razočaranje koje će osetiti kada se susretne sa izvornim govornikom, filmom, radio-emisijom ili muzikom biće veliko, stoga je neophodno da od početnog nivoa bude u kontaktu sa autentičnim jezikom.

\subsection{Važnost upotrebe autentičnog materijala u nastavi italijanskog jezika kao stranog jezika}

Pri prelasku na komunikativan pristup učenju jezika autentičan materijal postaje predmet velikog interesovanja zato što osim jezika oslikava aspekte „žive“ kulture sakupljene u svojoj dinamičnosti i u različitim aspektima sociolingvistike (Caon, 2011). Materijal se može smatrati autentičnim ako se radi o tekstu koji nije namenjen stranim studentima, već je, naprotiv, namenjen izvornim govornicima (Bonvino, 2004). Takvi materijali sami po sebi nisu imali didaktički cilj, već su bili rezultat korišćenja maternjeg jezika. Brojni su razlozi za primenu autentičnih audio-materijala, ali ćemo izdvojiti sintezu koju je napravio Kaon:

1) može da poboljša memorisanje leksike i strukture zahvaljujući „lakšem” ponavljanju slušanog, bez bojazni da se zapadne u dosadu ili u demotivisanost;

2) mogućnost da se uči o sociolingvističkim aspektima (žargon, kolokvijalizmi...);

3) mogućnost da se rade vežbe iz morfosintakse i fonetike;

4) mogućnost da se uči kako se nešto kaže i izrazi;

5) razvoj kulturnih znanja;

6) razvoj interkulturnih znanja;

7) razvoj interdisciplinarnih znanja.

CIVITAS | God. 6, Br. 1, 2016. 
Može se reći da su autentični lingvistički materijali neprocenjiva riznica zbog svoje primenjivosti u nastavi, a na nastavniku je zadatak da pažljivo izabere materijal koji će dovesti do razvoja komunikativnih kompetencija.

Komodi ističe da su video-materijali, u odnosu na tekstove koji su samo audio ili su samo napisani, obogaćeni jezikom pokreta, što omogućava učeniku da „percipira jedan globalni smisao poruke i da usvoji pragmatičko-funkcionalnu kompetenciju italijanskog jezika“ (1995: 14). Možemo se složiti sa Konvertinijem da je film „jedna vrsta otvorenog prozora ka kulturi“ (2006: 1). Učenici su na taj način izloženi prijatnom otkriću italijanskog jezika i kulture. „Video vodi, [...] unutar multidimenzione stvarnosti koja bi se inače teško mogla simulirati na času, stvarnosti u kojoj bivaju izloženi beskonačnosti komunikativnih situacija i primaju veliki broj stimulansa, kako jezičkih tako i kulturnih, koji sigurno mogu potpomagati ne samo njihov proces učenja već $i$ njihovo aktivno učešće na času i pre svega njihovu motivaciju da uče jezik“(Puntil, 2001/02: 7).

U prilog tome ide neurološka priroda čoveka. Balboni (1994) u svojoj knjizi Didattica dell'italiano a stranieri navodi da $83 \%$ informacija koje stižu u mozak dolazi kroz vizuelne kanale, dok samo 11\% dolazi kroz slušne. Ukazuje i na to da postoji rizik da se na taj način razume više kroz gledanje nego kroz uloženi jezički napor, te da je zarad didaktičkih ciljeva možda bolje insistirati na slušanju, barem u početnim fazama upotrebe govornog teksta (Isto).

Autentični audio-vizuelni materijali postaju „most između jezika u učionici i realnih jezičkih situacija" (Harrich, 2011: 321) i samim tim odlično sredstvo da se učenicima približi lingvistička i sociokulturna stvarnost Italije. Italijanska melodrama predstavlja jedan od najinteresantnijih doprinosa italijanskoj kuturi i sasvim je prirodno da se italijanskom jeziku može približiti upravo kroz operu. Snimljeni filmovi po poznatim melodramama jesu autentični audio-vizelni materijali koji će biti korišćeni u nastavi italijanskog jezika kao drugog stranog jezika. Operska arija je, dakle, početna tačka za aktivnosti slušanja/gledanja, čitanja, diskusije i gramatičkih vežbanja. 


\section{Predlozi nastavnih aktivnosti: didaktičko-metodička primena filma-opere}

Opere „Don Đovani“ i „Seviljski berberin“ izabrane su jer predstavljaju primere dveju različitih vrsta italijanske opere koje se mogu primeniti u nastavi italijanskog jezika kao stranog jezika. Uvodna faza gledanja filma ima za cilj da podstakne motivaciju studenata, znatiželju i empatiju prema drugoj kulturi. Pre gledanja važno je dati kratak sadržaj i što više informacija o filmu (o radnji, reditelju, glumcima/pevačima), kulturni, istorijski, prostorni i jezički kontekst jer se na taj način olakšava razumevanje filma-opere. Krenućemo od originalnog teksta, zatim ćemo preći prvo na parafrazirani tekst, koji možemo pojednostaviti upotrebljavajući objašnjenja arhaičnih termina ili težih idioma, a potom i na čitanje i objašnjenje originalne verzije, sa predlozima za vežbe i objašnjenja gramatičkih pravila, te ćemo doći do gledanja filma i naposletku do vežbi konverzacije.

\section{1. „Don Đovani“, muzika Mocart, libreto Da Ponte, režija Louzi}

I Faza - pre slušanja/gledanja filma -

- Nakon što su studenti upoznati sa kontekstom opere i sa nastavnim ciljem, nastavnik u ovoj fazi može pokazati plakate prvog izvođenja opere, može koristiti muzičke isečke najpoznatijeg dela opere, kartice sa ključnim rečima koje mogu da im posluže za smišljanje kratke priče itd.

- Studentima se zatim deli materijal sa parafraziranim tekstom originalne opere koji je uzet kao primer ne samo zbog svoje opštepoznatosti i izvanredne muzičke lepote već i zbog svoje jednostavne strukture. Tekst izgleda kao katalog, kao lista u kojoj dominira parataksična struktura.

Madamina, questo è il catalogo

Delle belle che amò il mio padrone;

Questo è un catalogo fatto da me, osservate, leggate con me.

In Italia sono seicentoquaranta, In Inghilterra sono duecentotrentuno, 
Italijanska arija - mogućnosti primene u nastavi italijanskog jezika... 65

Cento in Francia, in Turchia novantuno,

Ma in Spagna sono già milletré...

Fra queste ci sono contadine,

Cameriere, cittadine,

ci sono contesse, baronesse,

marchese, principesse,

e ci sono donne di ogni ceto

di ogni tipo, di ogni età (Carresi, Chiarenza, Frollano, 1998: 23).

- Sledeća vežba koju možemo izvesti na parafraziranom tekstu jeste postavljanje pitanja na koja studenti treba da odgovore sa tačno/netačno. Na primer: Il catalalogo è stato scritto da Don Giovanni? / Le donne amate in Inghliterra sono milletré? / Don Giovanni si innamora soltanto di donne aristocratiche?

II Faza - slušanje/gledanje filma - gde se traži od studenata da se skoncentrišu na slušanje muzike pokušavajući da što više razumeju tekst. Prelazi se zatim na čitanje i objašnjavanje originalnog teksta, a potom na novo slušanje kada im se zadaje jedna ili više vežbi:

- Prva moguća vežba jeste popunjavanje praznih mesta ispravnim glagolima. Na primer: Madamina, questo ... il catalogo / Delle donne che il mio padrone...

- Druga vežba može biti da se napišu antonimi prideva i imenica iz teksta. Na primer: contadina/cittadina, bionda/bruna, giovane/vecchia, bella/brutta...

- Treća vežba može biti ponavljanje gramatičkih pravila za upotrebu brojeva (osnovnih i rednih) u italijanskom jeziku, polazeći od brojeva koji su navedeni u ariji i povezujući ih sa nastavnim sadržajem koji prati znanje studenata na A2 nivou.

- Četvrta vežba može biti popunjavanje tabele traženim informacijama: mesto odvijanja radnje, imena aktera, vreme dešavanja radnje...

Nakon ove druge faze prelazi se na novo slušanje/gledanje filma pri čemu studenti mogu da pokušaju da pevaju ariju. 
III Faza - nakon gledanja/slušanja filma - nastavnik može da uvede studente u diskusiju postavljajući pitanja: Da li ste primetili sinhroniju između muzike i filmske sekvence? / Šta mislite o filmskoj scenografiji? / Šta mislite o glumcu koji je ujedno i pevač? / Šta mislite o filmu u kojem se peva od prve do poslednje sekvence?

U ovoj fazi se razvija veština govora preko diskusija o likovima ili o radnji opere, a može se sprovesti i vežba opisivanja predivne osobe koju je student upoznao. Radi razvoja veštine pisanja, studenti mogu u paru ili u grupi da napišu sastav do stotinu reči o najsimpatičnijem liku i da objasne zbog čega su se upravo za njega opredelili.

\section{2. „Seviljski berberin“, muzika Rosini, libreto Sterbini, režija Kosta}

Tekst iz Figarove arije dosta je jednostavan tako da ne zahteva autentično parafraziranje. I ovde je, kao i u Mocartovom „Don Đovaniju“, sintaksička struktura regularna, parataksična, glagoli su u prezentu, a logička struktura je vrlo jednostavna, što pogoduje izvođenju nastave za studente A2 nivoa. Ono što zahteva objašnjenja jeste jezička igra, to jest upotreba latinskog za reči poput factotum ( fac za facis+totum $=$ far tutto) ili drugih termina, danas neupotrebljavanih, kao što su vaglio za valgo (vredim), bottega za negozio (prodavnica) itd.

I Faza - pre slušanja/gledanja filma - čitanje parafraziranog teksta:

Largo al factotum

Della città

Presto in negozio

Che è già alba.

Ah, che bella vita,

Che piacere, che felicità

Per un barbiere

di qualità!

Bravo Figaro,

Bravo, bravissimo;

Sei davvero fortunato.

Pronto a fare tutto,

Sia la notte che il giorno

CIVITAS | God. 6, Br. 1, 2016. 
Sei sempre intorno, in giro (Carresi, Chiarenza, Frollano, 1998: 29).

- Prva aktivnost može biti vežba zasnovana na pitanjima sa više ponuđenih odgovora: Figaro è: 1. molto contento, 2.triste, 3. annoiato; Figaro parla: 1. di se, 2. del Conte, 3. di Rossina; Figaro è: 1 . un servitore, 2 . un pittore, 3 . un barbiere.

- Druga aktivnost koja može da se uradi tokom ove faze jeste komparacija opisnih prideva i apsolutni superlativ. Od studenata se može tražiti da naprave apsolutni superlativ u sledećim primerima: bello, buono, gentile, cattivo, severo, brutto...

II Faza - slušanje/gledanje filma - studenti prvo slušaju i gledaju film, a zatim je moguće zadati nekoliko aktivnosti:

- popunjavanje, tokom drugog slušanja, praznih mesta adekvatnim terminima. Na primer: Ah che bel... / che bel piacere / per un barbiere di...! / Pronto a ... tutto / la notte e il... / sempre d'intorno / in giro...;

- prepoznavanje i izdvajanje predloga u tekstu: Figaro qua, Figaro là, / Figaro su, Figaro giù, stavljajući ih uz odgovarajući prilog za mesto, na primer: vicino/qua; lontano/là (Carresi, Chiarenza, Frollano, 1998: 30);

- ispravljanje pogrešno otkucanih stihova: umesto zadatih Tutti mi cercano / Tutti mi trovano... treba napisati - Tutti mi chiedono / Tutti mi vogliono;

- pravilno raspoređivanje izmešanih stihova;

- izdvajanje iz teksta termina u vezi sa zanatom berberina.

Nakon ove druge faze prelazi se na novo slušanje/gledanje filmskog isečka. Studentima se pružaju nove kritičke informacije o filmu, a pozivaju se i da o njemu iznesu svoja razmišljanja.

III Faza - nakon gledanja/slušanja filma - nastavnik uvodi studente u diskusiju postavljajući im pitanja: Šta mislite o pozorišnom aspektu ovog filma? Da li i koliko muzika prati sliku filma? Može se voditi razgovor i o Figaru i njegovoj ulozi, studenti mogu sami zamisliti i napisati kraj arije, a mogu i neki deo arije da otpevaju (što često izaziva osmehe na njihovim licima, ali na taj način „udišu“ italijansku kulturu i jezik). 


\section{Zaključak}

U savremenim udžbenicima italijanskog jezika prisutni su kulturni i civilizacijski sadržaji u sklopu nastavnog programa, ali u velikom broju udžbenika nisu prisutne italijanske opere kao autentičan didaktički materijal. Postoje pojedine teškoće u primeni takvog materijala u nastavi, ali izborom odgovarajućeg dela operske arije i odgovarajućeg didaktičkog materijala prilagođenog nivou znanja studenata, poteškoće se mogu svesti na minimum. U takvom slučaju, parafrazirani stihovi italijanskih arija u velikoj meri olakšavaju rad na tekstu, a kombinovani sa vežbama slušanja/gledanja na času omogućuju studentu da unapređuje svoju kulturnu i komunikativnu kompetenciju. Sa pedagoške strane gledišta film umanjuje distancu između studenta i nastavnog sadržaja i pokazalo se da studenti imaju mnogo više motivacije za diskusiju o temama koje su im približene filmom. Pored toga, italijanska muzika smanjuje psihološke barijere pri učenju stranog jezika. Stoga je potrebno istaći koliko je korisno pravilno upotrebiti autentičan materijal, naročito na početnim nivoima, kako bi se stekla što šira lingvistička i sociokulturna znanja iz italijanskog jezika i kulture.

\section{Literatura}

Balboni, P. E. (1994). Didattica dellitaliano a stranieri. Roma: Università per stranieri di Siena, Bonacci.

Balboni, P. E., Daloiso, M. (2007). Civiltà Italia. Percorsi di cultura e civiltà italiana per stranieri. Perugia: Guerra Edizioni.

Bonvino, E. (2004). I materiali didatticiper l'insegnamento dell'italiano L2: criteri di selezione. ICON.

Bugarski, R. (1997). Jezik u kontekstu. Beograd: Biblioteka XX vek.

Caon, F. (2011): L'italiano parla Mogol: imparare l'italiano attraverso $i$ testi delle sue canzoni. Perugia: Guerra Edizioni.

Comodi, A. (1995). Matteriali autentici: selezione e uso nella didattica dell'italiano come lingua straniera. Perugia: Guerra Edizioni.

Convertini, T. (2006). Insegnare lingua con il cinema: una prospettiva alternativa. Italica 83,1, pp 22-23.

CIVITAS | God. 6, Br. 1, 2016. 
Carresi, S., Chiarenza, S., Frollano, E. (1998). L'italiano allopera. Attività linguistiche attraverso 15 arie famose. Roma: Bonacci.

Krasner, I. (1999). The Role of Culture in Language Teaching. Dialogue on Language Instruction, 13(1-2): 79-88.

Harrich, K. (2011). Il notizario ovvero l'importanza dell'uso di materiali autentici nell'insegnamento-apprendimento linguistico. Italiano LinguaDue, 2.(2), 321.

Puntil, D. (2001). Lutilizzo didattico del video nella classe di italiano L2: un'unità didattica basata sul film Le fate ignoranti di Ferzan Ozpetek. Università degli studi di Bologna.

Vujović, A. (2007). Obrazovanje profesora stranih jezika u oblasti strane kulture. Pedagogija, 62(4), 657-666.

Vučo, J. (2013). O nekim specifičnostima interkulturne razmene u savremenoj nastavi stranih jezika. u: Jezici i kulture u vremenu i prostoru (II/1), ur. S. Gudurić i M. Stefanović (Novi Sad: Filozofski fakultet): 273-379.

\section{L'ARIA ITALIANA - CONSIGLI PER LE ATTIVITÀ DIDATTICHE NELL'INSEGNAMENTO DELLA LINGUA E DELLA CULTURA ITALIANA COME LINGUA STRANIERA PER LIVELLO A2}

Riassunto: Il presente lavoro si occupa dei consigli per le attività didattiche nell'insegnamento dell'italiano come lingua straniera per livello A1/A2 attraverso il melodramma. Laria è il punto di partenza per attività di ascolto/visione, di lettura, di discussione e di esercizi grammaticali. Negli esempi di parafrasi del testo dellaria in italiano contemporaneo gli studenti hanno possibilità di apprendere la lingua e anche di essere a contatto del ricco patrimonio culturale di Italia. L'utilizzo dellopera-film, come il materiale autentico didattico, gli studenti fanno parte della cultura italiana che influenza positivamente la motivazione degli studenti per arricchire la loro competenza comunicativa e la loro competenza interculturale.

Parole Chiavi: opera-film, materiale autentico, didattazione, competenza culturale, competenza comunicativa. 